\title{
Análise biomecânica da solidarização de tendões para reconstrução do ligamento cruzado anterior
}

\author{
Biomechanic analysis of the sewed tendons for the reconstruction of the \\ anterior cruciate ligament
}

Edmar Stieven Filho ; Osvaldo Malafaia, ECBC-PR ${ }^{5}$; Jurandir Marcondes Ribas-Filho, TCBC-PR5; Otaviano Esteves dos Santos Diniz ; Paulo César Borges33; Mauro Albano ${ }^{3}$; Márcio Kume ${ }^{1}$; João luiz Vieira da Silva ${ }^{1}$; Mario Namba ${ }^{4}$

\section{RES U M O}

\begin{abstract}
Objetivo: Avaliar a diferença do comportamento mecânico de tendões flexores solidarizados e não solidarizados para verificar se a solidarização tem função efetiva. Métodos: Vinte e quatro tendões digitais bovinos frescos foram usados. Para determinar a área da secção transversal utilizou-se alginato. Dez tendões foram solidarizados seguindo as orientações do fabricante; outros 10 pares não. Foram desenvolvidas garras para fixação dos enxertos à máquina universal para simulação da fixação, sendo a superior bipartida e de passagem controlada dos pinos e a inferior com dentes alternados. Resultados: A carga máxima dos corpos de prova não solidarizados foi de 849,4 $\mathrm{N} \pm 386,8$ a área 30,4 $\mathrm{mm}^{2} \pm 7,7$, tensão de $29 \pm 17 \mathrm{Mpa}$. Os solidarizados obtiveram carga máxima de $871,8 \mathrm{~N} \pm 484,9$ área $35 \mathrm{~mm}^{2} \pm 5,8$, tensão de $24 \pm 10 \mathrm{Mpa}$. Não houve diferença estatística entre os dois grupos ( $\left.p>0,05\right)$. Conclusão: A distribuição de probabilidade mostra que para $400 \mathrm{~N}$ os tendões não solidarizados apresentam confiabilidade de $83,8 \%$ e os solidarizados de $78,5 \% \%$.
\end{abstract}

Descritores: Ligamento cruzado anterior. Fêmur. Dispositivos de fixação ortopédica. Mecânica, tendões.

\section{INTRODUÇÃO}

A reconstrução do ligamento cruzado anterior - uma das operações eletivas mais comuns dos membros inferiores -, é fator determinante para a obtenção de melhores resultados no retorno à prática esportiva em pacientes com instabilidade anterior do joelho'.

A técnica de fixação transversal RigidFix ${ }^{\circledR}$, para tendões flexores, tem sido utilizada na reconstrução do ligamento cruzado anterior. Um dos seus passos constitui-se no preparo do enxerto de tendões flexores, limpeza, sutura das quatro extremidades livres e solidarização dos tendões. A solidarização consiste no processo de colocar dois tendões paralelos e suturá-los, na tentativa de transformá-lo em um corpo único. Esse processo exige tempo e dedicação de um dos membros da equipe cirúrgica para que seja executado ${ }^{2}$.

Este trabalho tem os objetivos: 1. verificar a diferença do comportamento mecânico de tendões flexores solidarizados e não solidarizados e avaliar a carga máxima suportada; 2 . durante o teste dos tendões, analisar se eles se comportam de maneira independente ou como um úni- co corpo de prova; 3. se há influência da solidarização; 4. verificar a probabilidade de falha.

\section{MÉTODOS}

Foram adquiridos 24 tendões digitais bovinos frescos provenientes do cruzamento industrial entre as raças simental e nelore, todos machos com três anos de idade. Inicialmente os tendões eram dissecados em frigorífico por um dos autores previamente treinado (Figura 1). Depois de dissecados esses tendões eram divididos em dois, formando pares, simulando os tendões flexores humanos. Quatro tendões foram desprezados.

Os pares foram colocados lado a lado e cada par foi denominado "corpo de prova". Para determinar-se a área da secção transversal dos corpos de prova, eles foram suturados nas extremidades com um fio cirúrgico Ethibond $\circledast$ 2 e colocados na posição de pêndulo com carregamento de 20N. Nesta condição adquiriram-se suas impressões em pasta de alginato (Alginato Jeltrade Tipo II Presa Normal) ${ }^{3}$ para formar um molde do corpo de prova que, após alguns

Trabalho realizado na Universidade Tecnológica Federal do Paraná - UTFPR, no Centro de Traumatologia Esportiva e Artroscopia (CTEA) de Curitiba e Programa de Pós-Graduação em Princípios da Cirurgia do Hospital Universitário Evangélico de Curitiba/Faculdade Evangélica do Paraná, Curitiba, PR, Brasil.

1. Ortopedista do CTEA, Curitiba, PR, Brasil. 2. Engenheiro mecânico da UTFPR, Curitiba, PR, Brasil. 3. Doutor em Engenharia Mecânica pela Universidade Federal de Santa Catarina; orientador de doutorado da UTFPR, Curitiba, PR, Brasil. 4. Ortopedista grupo CTEA, coordenador da pós-graduação em Artroscopia - UFPR, Curitiba, PR, Brasil. 5. Professor Permanente do Programa de Pós-Graduação em Princípios da Cirurgia do Hospital Universitário Evangélico de Curitiba/Faculdade Evangélica do Paraná, Curitiba, PR-BR. 


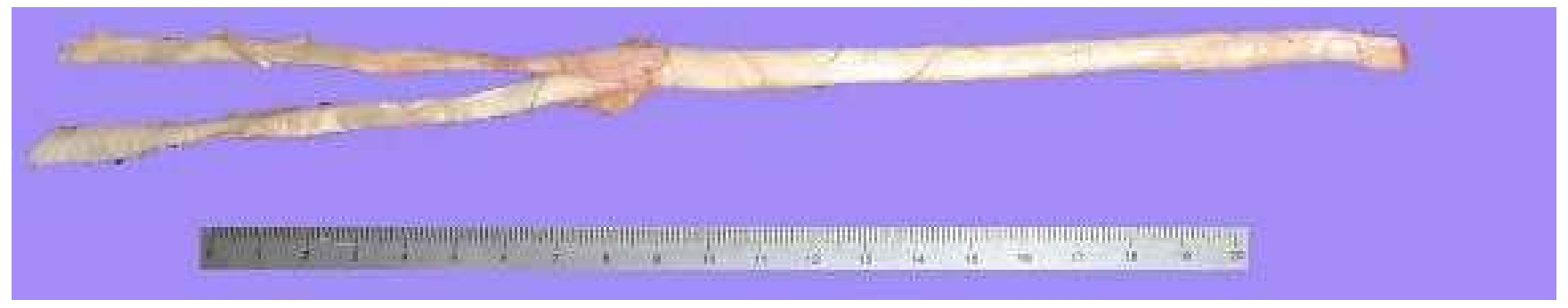

Figura 1 - Tendão digital bovino dissecado.

segundos, ficava com consistência borrachosa. Neste ponto o alginato era retirado, mantendo a impressão do corpo de prova. Esse molde era seccionado transversalmente.

As secções geradas pelo molde de alginato eram digitalizadas com resolução de 600dpi por digitalizador HP J5780®.

As áreas de secção transversal dos moldes foram medidas com auxílio do programa Image-Pro Plus, que através das imagens digitalizadas tem a capacidade de fornecer uma medida de área (Figura 2).

A parte da secção transversa mais fina de cada corpo de prova foi selecionada para cálculo da área. Como os pares de tendões são dobrados ao meio para formar o enxerto quádruplo, a área mínima de cada um dos pares foi multiplicada por dois.

\section{Preparação dos corpos de prova}

Os tendões foram preparados na mesa auxiliar, sendo colocado um sobre o outro e dobrando-os sobre um fio de Ethibond® 5 (enxerto quádruplo). Dez pares de tendões foram solidarizados com fio Ethibond ${ }^{\circledR} 2$ na extremidade proximal dos enxertos, seguindo as orientações do fabricante (Figura 3)2. Outros dez não foram solidarizados.

Foram desenvolvidas garras para fixação dos enxertos quádruplos à máquina universal para simulação da fixação.

A garra superior se caracterizava por ser bipartida e de passagem controlada do pino transverso. Esta garra teve como objetivo controlar a incerteza do posicionamento do pino durante os testes na máquina de ensaio. O implante original era um pino transverso, à base de ácido polilático; o pino para teste foi usinado em aço para formar um sistema infalível, evitando que possíveis falhas no pino interferissem na avaliação das características biomecânicas (Figura 4).

A garra inferior de dentes alternados foi fabricada de forma a evitar o escorregamento dos tendões durante ao ensaio.

Para aumentar o agarre do sistema aos corpos de prova foi utilizada uma gaze em torno do tendão para evitar seu escorregamento devido ao desprendimento natural de gordura durante o teste 4 .

Os enxertos quádruplos foram divididos em dois grupos: os não solidarizados - corpos de prova de um a dez (CP01 ao CP10) e os solidarizados (CP11 ao 20). Foram levados à tração utilizando-se da garra superior bipartida de passagem controlada e a garra inferior de dentes alternados.

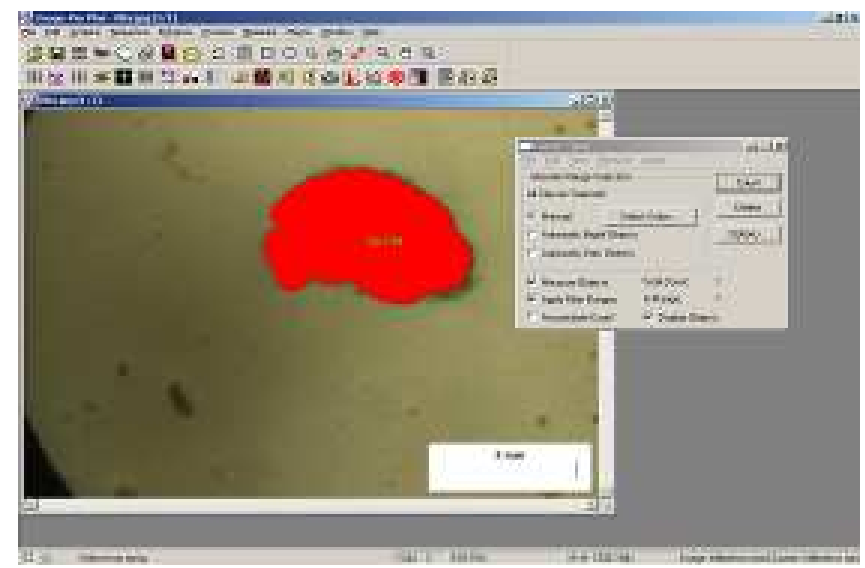

Figura 2 - Exemplo de imagem produzida pelo programa ImagePro Plus.

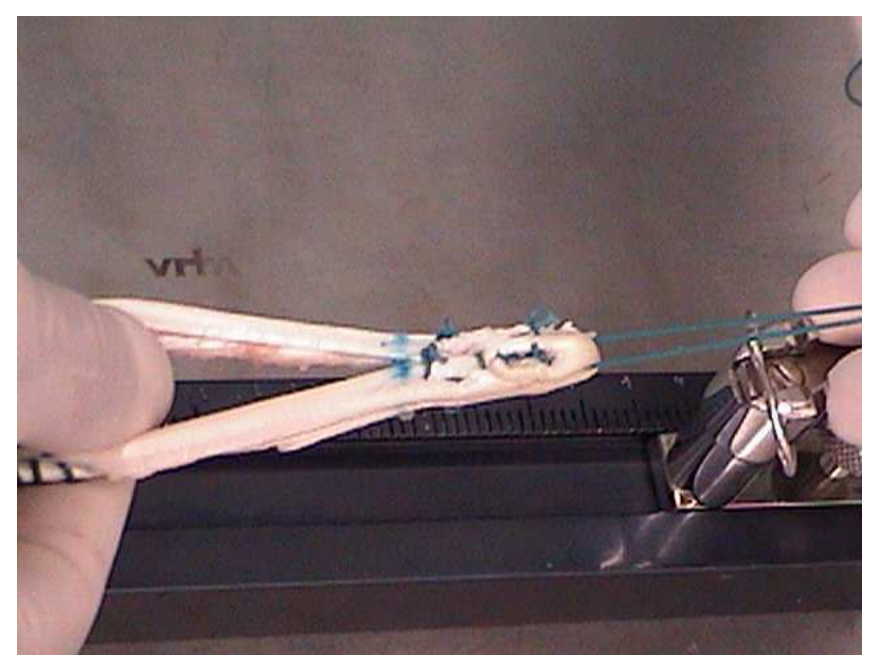

Figura 3 - Momento da solidarização dos tendões.

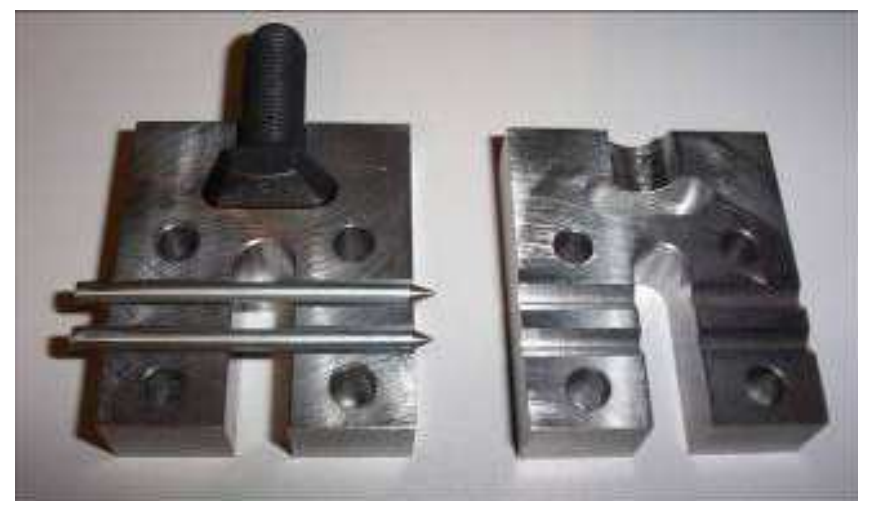

Figura 4 - Garra superior bipartida. 
Os ensaios de tração axial foram realizados no Laboratório de Biomecânica da UTFPR (Universidade Tecnológica Federal do Paraná). Foi utilizada máquina universal de ensaios MTS 810 com célula de carga modelo 661.19F-02 com capacidade para $10 \mathrm{kN}$ da MTS Systems Corporation e velocidade de ensaio de $40 \mathrm{~mm} / \mathrm{min}$. Os resultados de força máxima e de força versus deslocamento foram obtidos (Figura 5).

Os resultados foram submetidos à análise de variância ANOVA. Também foi realizada a probabilidade utilizando-se a distribuição de Weibull, para comparar a probabilidade de falha entre os dois grupos, construindo-se o intervalo de $95 \%$ de confiança para a confiabilidade na carga máxima de $400 \mathrm{~N}$. Foi considerado falha, a rotura do primeiro tendão, ou seja, o ápice do primeiro grande pico. Os testes foram realizados com os programas Microsoft $₫$ Excel XP e Origin Pro® 6.1.

\section{RESULTADOS}

Neste estudo foram considerados 20 pares de tendões bovinos dos quais 10 foram solidarizados e os outros 10 não solidarizados. A variável de interesse foi a carga máxima dos corpos de prova. Quatro tendões foram desprezados por erro na dissecção.

Os resultados dos testes estão descritos em tabela com os valores da tensão ( $\boldsymbol{\square})$, área da seção transversal (Ao) e força (N) (Tabelas 1 e 2).

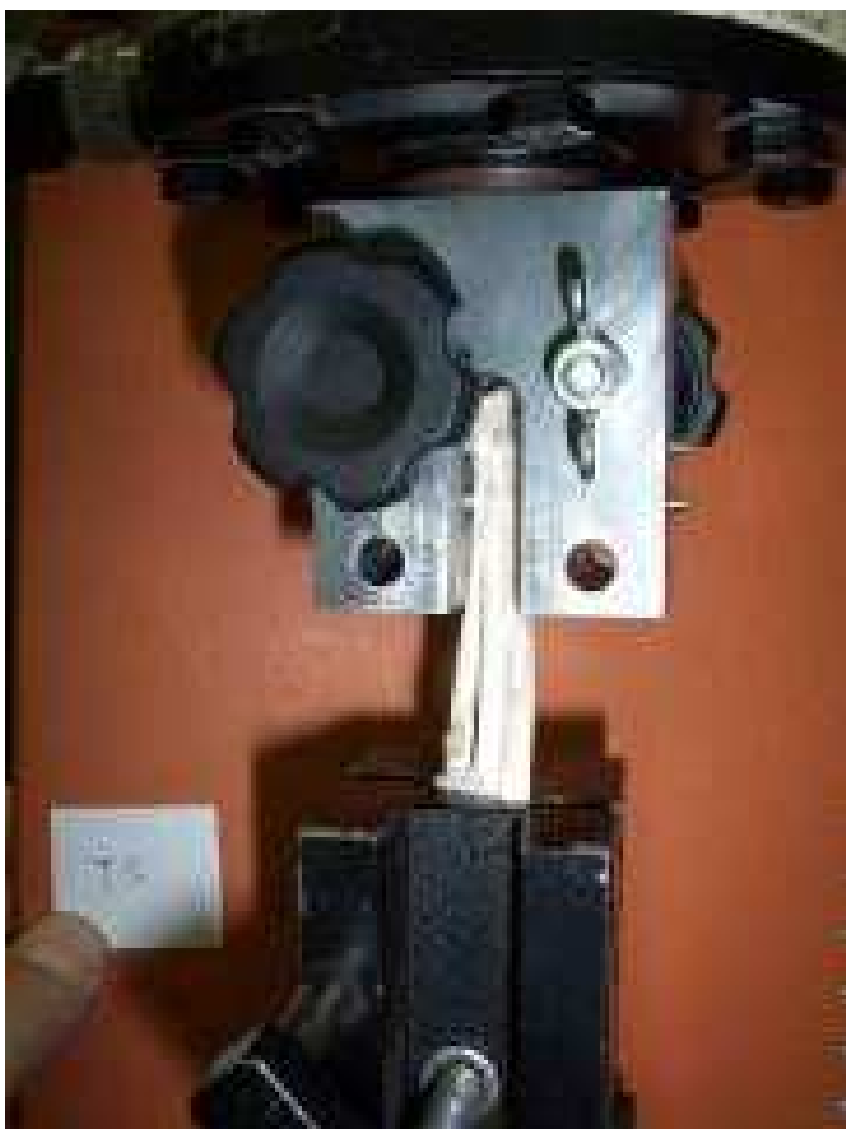

Figura 5 - Momento de montagem do teste do corpo de prova.
Tabela 1 - Resultados dos experimentos em tendões solidarizados $(n=10)$.

\begin{tabular}{lccc}
\hline & Força(N) & Ao $\left(\mathrm{mm}^{2}\right)$ & $\square(\mathrm{MPa})$ \\
\hline Média & 30,4 & 871,8 & 29 \\
DP & 484,9 & 7,7 & 7,4 \\
Mínimo & 179,5 & 22,4 & 7,9 \\
Máximo & 1456,8 & 47,2 & 56,1 \\
\hline
\end{tabular}

Nota: $n=$ número de testes, $D P=$ desvio-padrão, $A_{o}=$ área, $\quad \square=$ tensão

Tabela 2 - Resultados dos experimentos em tendões não solidarizados $(n=10)$.

\begin{tabular}{lccc}
\hline & Força(N) & Ao $\left(\mathrm{mm}^{2}\right)$ & $\square(\mathrm{MPa})$ \\
\hline Média & 849,4 & 35 & 24,3 \\
DP & 386,8 & 5,8 & 10,3 \\
Mínimo & 236,4 & 26,8 & 6,5 \\
Máximo & 1134 & 44,2 & 35,7 \\
\hline Nota: $n=$ número de testes, $D P=$ desvio-padrão, $A_{\circ}=$ área, & $\square=$ tensão
\end{tabular}

A carga máxima dos corpos de prova não solidarizados foi de $849,4 \mathrm{~N} \pm 386,8$ e dos solidarizados $871,8 \mathrm{~N} \pm 484,9$. Pelo teste ANOVA não houve diferença estatística entre os dois grupos $(p=0,9)$.

A rotura dos corpos de prova se deu na região dos pinos, aonde eles são dobrados $180^{\circ}$ para formação do tendão quádruplo.

$\mathrm{Na}$ análise dos gráficos, foi considerado comportamento independente, quando se obteve dois grandes picos no gráfico. Nesses casos se considera que a carga foi depositada inicialmente sobre um dos tendões do corpo de prova e após o pico máximo, ela foi transferida ao segundo tendão, formando um segundo pico (Figura 6).

Foi considerado como comportamento único do tendão quando houve apenas um pico de força (Figura 7). Dos 20 testes, 14 tiveram comportamento independente.

Os resultados em relação ao número de picos estão representados na tabela 3 .

Nos casos com três picos, considerou-se como sendo o inicial referente à rotura do fio da solidarização, pois este tem baixa amplitude (Figura 8). Os valores de força para os picos onde ocorreu a rotura do fio foram de $297 \mathrm{~N}$ e $288 \mathrm{~N}$.

Nos tendões solidarizados que apresentaram dois picos, o primeiro foi sempre maior que o segundo. O mesmo não ocorreu em três casos dos tendões não solidarizados com o segundo pico maior que o primeiro.

Tabela 3 - Análise dos gráficos em relação ao números de picos de força.

\begin{tabular}{|c|c|c|c|}
\hline Condição & Um pico & Dois picos & Três picos \\
\hline Não solidarizado & 1 & 9 & 0 \\
\hline Solidarizado & 5 & 3 & 2 \\
\hline
\end{tabular}


A distribuição de Weibull de dois parâmetros mostrou-se adequada em relação aos dados obtidos para os tendões solidarizados e não solidarizados (Tabela 4).

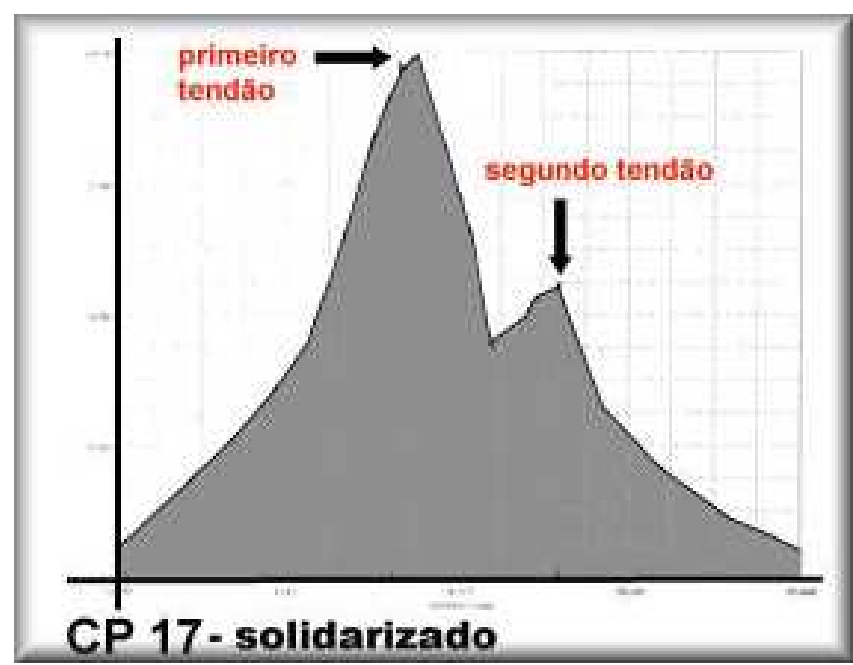

Figura 6 - Comportamento independente dos tendões.

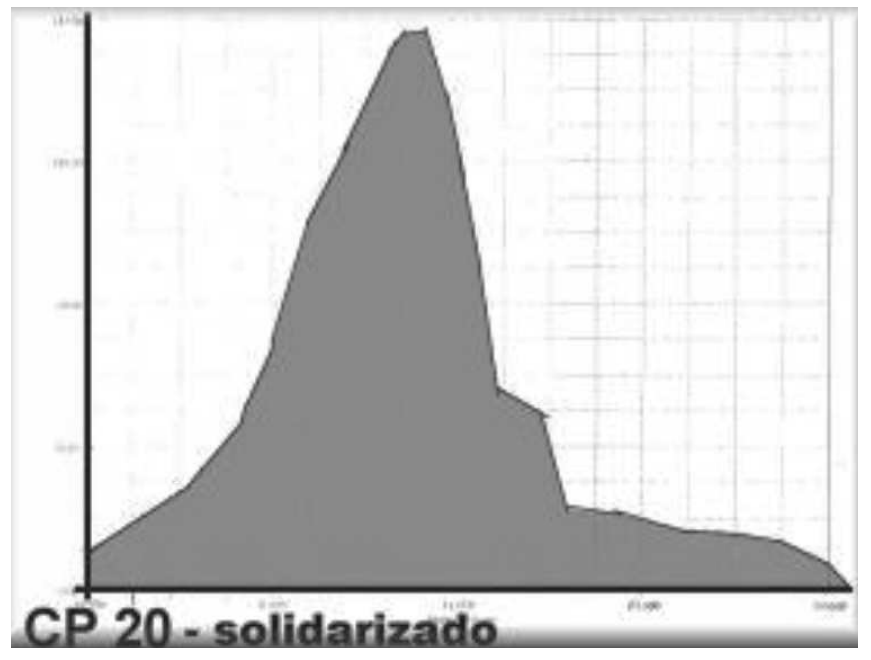

Figura 7 - Comportamento único dos tendões.

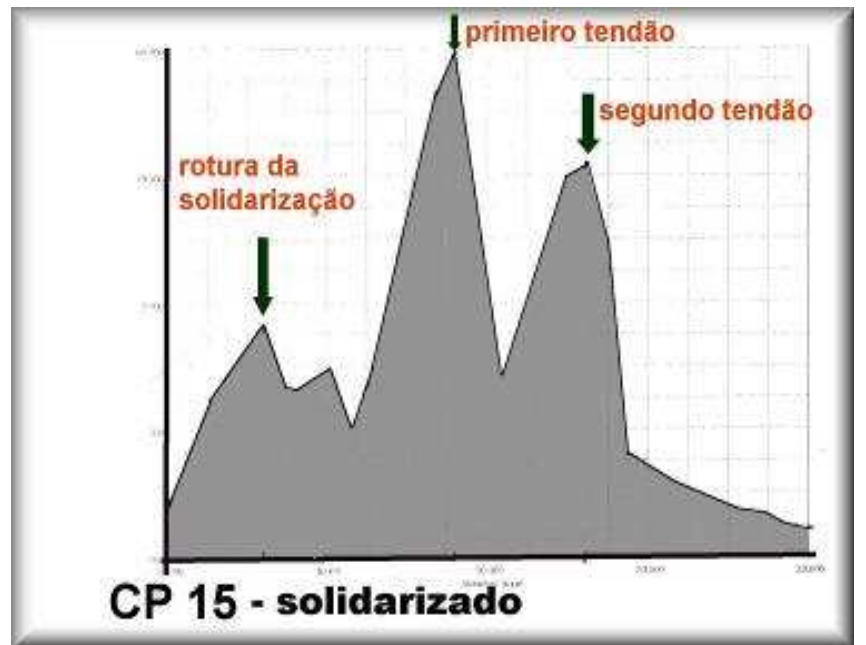

Figura 8 - Tendões independentes onde o $1^{\circ}$ pico refere-se à solidarização.
Os tendões não solidarizados apresentaram valor de â maior indicando menor dispersão dos resultados que pode refletir na confiabilidade. Ambos os conjuntos de dados ajustaram-se perfeitamente à distribuição de Weibull de dois parâmetros (valor alto de $\mathrm{r}^{2}$ ).

No grupo não solidarizado estimou-se que a probabilidade de ruptura com uma carga de até $400 \mathrm{~N}$ era igual a 0,1794. O intervalo de 95\% de confiança para esta probabilidade foi de $(0,1449-0,2210)$, indicando que existe $95 \%$ de chance de que este intervalo contenha a probabilidade de ruptura para uma carga de até $400 \mathrm{~N}$ em tendões não solidarizados. Isto equivale a dizer que a confiabilidade em $400 \mathrm{~N}$ correspondeu a 0,8206 com intervalo de $95 \%$ de confiança $(0,7790$ - 0,8551).

Já para o grupo solidarizado estimou-se que a probabilidade de ruptura com carga de até $400 \mathrm{~N}$ era igual a 0,2336. O intervalo de $95 \%$ de confiança para esta probabilidade foi de $(0,1978-0,2747)$, indicando que existe $95 \%$ de chance de que este intervalo contenha a probabilidade de ruptura para carga de até $400 \mathrm{~N}$ em tendões solidarizados. Isto equivale a dizer que a confiabilidade em $400 \mathrm{~N}$ correspondeu a 0,7664 com intervalo de 95\% de confiança $(0,7253-0,8022)$

Apesar de que a confiabilidade para carga de $400 \mathrm{~N}$ ter sido $7 \%$ maior no grupo não solidarizado em relação ao grupo solidarizado $(0,8206$ dividido por $0,7664)$, houve uma interseção dos intervalos de $95 \%$ de confiança, indicando a não rejeição da hipótese nula de mesma confiabilidade na carga máxima de $400 \mathrm{~N}$ (Figura 9).

Tabela 4 - Análise de Weibull dos dados e o ${ }^{2}$

\begin{tabular}{lccc}
\hline Condição & Alfa $(\boldsymbol{\alpha})$ & $\operatorname{Beta}(\boldsymbol{\beta})$ & $\mathbf{r}^{2}$ \\
\hline Solidarizado & 1012,7 & 1,52 & 0,97 \\
Não solidarizado & 984,7 & & 0,97 \\
\hline
\end{tabular}

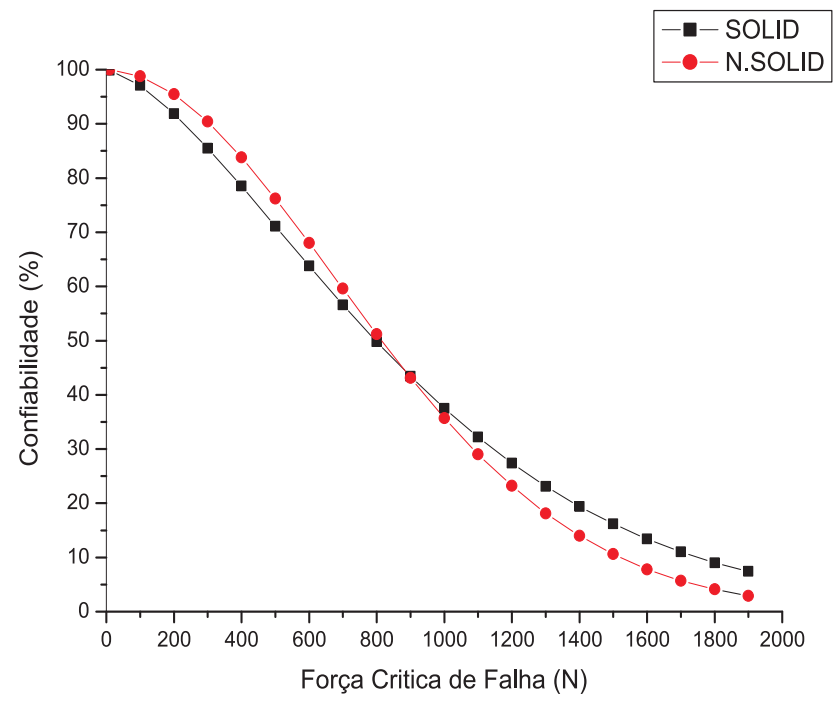

Figura 9 - Distribuição de probabilidade de Weibull. 


\section{DISCUSSÃO}

A escolha pelo tendão extensor digital bovino se fez por serem de fácil obtenção, baixo custo e por possuírem semelhança quanto às propriedades mecânicas do tendão humano. Embora existam algumas diferenças, elas não interferem na análise comparativa. Assim, os enxertos de tendão digital bovino podem ser considerados como substitutos de tendões flexores humanos em ensaios de tração ${ }^{5}$. Utilizaram-se tendões frescos (resfriados apenas) visto que seu armazenamento e esterilização podem influenciar nas propriedades mecânicas do enxerto ${ }^{6,7}$.

Poucos estudos foram realizados no desenvolvimento de garras para testes de carga em tendões. Na sua maioria, os testes são feitos com corpos de prova tendãoosso, onde o tendão está fixo à uma parte óssea, e a preensão da garra se dá no baguete ósseo e não no tendão.

Para evitar que os dados de força versus deslocamento sejam poluídos, tentou-se ao máximo limitar as variáveis do sistema ${ }^{8-10}$. Sendo assim, foi necessário o desenvolvimento de um sistema de garras e simuladores de fixação com alta resistência, para que a falha ocorresse no tendão, evitando-se novas variáveis.

Para o sistema de fixação superior foi confeccionado um dispositivo bipartido de passagem controlada, no qual era possível controlar a passagem dos pinos de aço, evitando-se incertezas na passagem dos pinos que poderiam acarretar dificuldade na análise dos dados. A garra inferior de dentes alternados foi eficaz em contornar o escorregamento do tendão; porém, isso só se alcançou após a utilização de uma gaze em torno do tendão pois ele desprende gordura durante o teste ${ }^{5}$.

A obtenção da área dos corpos de prova pela secção transversal do Alginato Jeltrade Tipo II demonstrou ser técnica fácil e eficaz. O único cuidado foi a medição da área imediatamente após a impressão, pois o tendão tendia a retrair-se durante a secagem. Isto também foi observado por outros autores ${ }^{4}$.

Como esperado, durante os testes, a rotura do tendão se deu na região dos pinos, por concentração de tensão, uma vez que eles são dobrados $180^{\circ}$ neste ponto.

Quanto à necessidade de solidarização, pôde-se notar que foi obtida cooperação mútua em cinco pares solidarizados e em apenas um não solidarizado. Apesar da pequena amostra, este fato sugere que a solidarização tenha alguma eficácia no comportamento biomecânico do tendão quádruplo, ou seja, faz com que ele tenda a trabaIhar como um único tendão.

A maioria dos corpos de prova não solidarizados tiveram dois grandes picos no gráfico do mesmo teste. Supõe-se com isso que os dois tendões do enxerto quádruplo estivessem atuando separadamente.

Mesmo nos cinco casos em que os tendões solidarizados tiveram mais de um pico de tensão, o primeiro foi maior que o segundo. Isso não aconteceu em dois casos dos tendões não solidarizados. O segundo foi maior que o primeiro, indicando que o sistema falhou antes de atingir sua resistência máxima.

Nos casos de dois grandes picos de tensão, fica claro que os tendões trabalharam de forma independente. Em dois casos os solidarizados apresentaram três picos de tensão, sendo o primeiro muito menor em relação aos outros. Neles, o primeiro pico se referia à rotura do fio da solidarização.

Também é possível dizer que a solidarização dos tendões possui característica de que, quando não auxilia na execução mútua dos tendões, dá a falsa impressão de que o enxerto está funcionando corretamente até valores de carregamento de $300 \mathrm{~N}$ - onde o fio se rompe afrouxando o sistema. Este tipo de falha ocorreu em três experimentos, mostrando a importância da pré-tensão do tendão no trans-operatório antes da fixação tibial. Outra hipótese seria a de usar um fio com resistência menor para que diminua essa margem de $300 \mathrm{~N}$ da "acomodação" da solidarização.

Neste mesmo enfoque pôde-se analisar a distribuição de probabilidade de Weibull. Observou-se que para $400 \mathrm{~N}$ os tendões não solidarizados apresentavam confiabilidade de $82,06 \%$, ou seja, com base nos dados deste trabalho, $82,06 \%$ dos casos terão sucesso em carregamento até este valor. Já para os tendões solidarizados este valor é de $76,64 \%$ para $400 \mathrm{~N}$, porém esta diferença não foi estatisticamente significante (interseção dos intervalos de $95 \%$ de confiança).

As evidências indicaram, que esse resultado pior dos tendões solidarizados ocorreu devido à rotura do fio de solidarização, pois após $800 \mathrm{~N}$ a confiabilidade dos solidarizados supera a dos não solidarizados.

A carga suportada por qualquer sistema de fixação deve ser de no mínimo $400 \mathrm{~N}$ nas primeiras três semanas de pós-operatório para possibilitar a reabilitação mais adequada. Nos testes teve-se como carga máxima para os enxertos não solidarizados 849,2 $\mathrm{N} \pm 386,7$ e dos solidarizados foi de $871,5 \mathrm{~N} \pm 484,8$ não havendo diferença estatística entre os dois grupos ( $p>0,05)$. Neste trabalho não foram avaliadas as características do implante original e da estrutura óssea humana, mas foi usado enxerto de extensores bovinos que teem proximidade biomecânica com o enxerto de tendões flexores humano ${ }^{3}$.

A carga máxima dos corpos de prova não solidarizados foi de $849,4 \mathrm{~N} \pm 386,8$ e dos solidarizados de $871,8 \mathrm{~N} \pm 484,9$ e não houve diferença entre os dois grupos; Os braços dos tendões do enxerto quádruplo tendem a trabalhar de forma mecanicamente independente, em especial os não solidarizados; Nos tendões solidarizados existe o risco da fixação depositar sua resistência no fio da solidarização, causando afrouxamento do sistema com carga de aproximadamente $300 \mathrm{~N}$; A distribuição de probabilidade mostrou que para $400 \mathrm{~N}$ os tendões não solidarizados apresentam confiabilidade de $82,06 \%$ e os solidarizados de $76,64 \%$, não sendo esta diferença estatisticamente significante. 


\section{A B S T R A C T}

Objective: To evaluate the difference of the mechanical behavior of bended tied (sewed) and not tied hamstring tendons in order to evaluate if it has any effective function. Methods: Twenty-four fresh bovine digital tendons had been used. Alginate to determine the area of the tendon transversal section was used. Ten bovine tendons had been bended and tied following the manufacturer orientation, ten others pairs had not been tied. Claws had been developed for the grafts fixation to the universal machine, for the setting simulation. The superior one was characterized to be bipartite and to have controlled passage for the pins and the inferior claw is characterized to have alternating teeth. Results: The maximum load of the not tied samples of the test was $849,4 \mathrm{~N} \pm 386,8$ the area was 30,4 $\mathrm{mm}^{2} \pm 7,7$, and $29 \pm 17 \mathrm{Mpa}$ of tension. The tied ones had gotten maximum load of $871,8 \mathrm{~N} \pm$ 484,9 , area of $35 \mathrm{~mm}^{2} \pm 5,8$, and $24 \pm 10 \mathrm{Mpa}$ of tension. It did not have statistical difference between the two groups (p>0,05). Conclusion: The probability distribution showed that with $400 \mathrm{~N}$ the not tied tendons represents $83,8 \%$ of trustworthiness and the tied ones represents $78,5 \%$.

Key words: Anterior cruciate ligament. Femur. Orthopedic fixation device. Mechanics, tendons.

\section{REFERÊNCIAS}

1. Cohen M, Abdalla RJ, Ejnisman B, Filardi MS, Amaro JT. Estudo comparativo no tratamento das lesões do ligamento cruzado anterior no esporte. Rev Bras Ortop. 1997;32(5):337-41.

2. Chapman J. E. Soft Tissue Acl Reconstruction Procedure. [disponivel na internet] 2005. http://www.jnjgateway.com/public/USENG/ Rigidfix_ST.pdf

3. Donahue TLH, Gregersen C, Hull ML, Howell SM. Comparison of Viscoelastic Structural, and Material Properties of Double-Looped Anterior Cruciate Ligament Grafts Made From Bovine Digital Extensor and Human Hamstring Tendons. J Biomech Eng. 2001; 123(2):162-9.

4. Goodship AE, Birch HL. Cross sectional area measurement of tendon and ligament in vitro: a simple, rapid, non-destructive technique. J Biom. 2005; 38:605-8.

5. Silva JLV, Tavares Filho GS, Namba MM, Pereira Filho FA, Barbosa MA, Albano M, Neves JK, Skroch GP. Estudo biomecânico, "in vitro", em ovinos, da fixação femoral do tendão patelar na reconstrução do LCA: comparação entre parafusos metálicos de interferência e a fixação sob pressão com bloco ósseo cônico. Rev Bras Ortop. 2003; 38(7):400-9.

6. Matthews LS; Ellis D. Viscoelastic properties of cat tendon: Effects of time after death and preservation by freezing. J Biomech. 1968; 65-71

7. Xerogeanes JW, Fox RJ, Takeda Y, Kim HS, Ishibashi Y, Carlin GJ, Woo SL. A functional comparison of animal anterior cruciate ligament models to the human anterior cruciate ligament. Ann Biomed Eng. 1998 May-Jun;26(3):345-52.
8. Noyes FR, Butler DL, Grood ES, Zernicke RF, Hefzy MS. Biomechanical analysis of human ligament grafts used in kneeligament repairs and reconstructions. J Bone Joint Surg Am. 1984 Mar;66(3):344-52.

9. Ahmad CS, Gardner TR, Groh M, Arnouk J, Levine WN. Mechanical properties of soft tissue femoral fixation devices for anterior cruciate ligament reconstruction. Am J Sports Med. 2004 AprMay;32(3):635-40.

10. Noyes FR, Butler DL, Paulos LE, Grood ES. Intra-articular cruciate reconstruction. I: Perspectives on graft strength, vascularization, and immediate motion after replacement. Clin Orthop Relat Res. 1983 Jan-Feb;(172):71-7.

Recebido em 09/01/2009

Aceito para publicação em 10/03/2009

Conflito de interesse: nenhum

Fonte de financiamento: nenhuma

\section{Como citar este artigo:}

Stieven Filho E, Malafaia O, Ribas-Filho JM, Diniz OES, Borges PC, Albano M, Kume M, Silva JLV, Namba M. Análise biomecânica da solidarização de tendões para reconstrução do ligamento cruzado anterior. Rev Col Bras Cir. [periódico na Internet] 2010; 37(1). Disponível em URL: http://www.scielo.br/rcbc

\section{Endereço para correspondência:}

Edmar Stieven Filho

ipem@evangelico.org.br 